\title{
DO PRAGMATISMO DE MORRIS, CARNAP E QUINE AO NEOPRAGMATISMO DE RICHARD RORTY
}

\author{
Arnon Pereira Dos Santos ${ }^{1}$
}

RESUMO: O objetivo deste escrito consiste em apresentar características da filosofia pragmática de Charles Morris, Rudolf Carnap e a mediação da filosofia de Quine até o neopragmatismo de Richard Rorty. A pergunta que nos conduzirá como questão norteadora da pesquisa é a seguinte: como se dá o pragmatismo de Morris e Carnap e a mediação da contribuição de Quine ao neopragmatismo de Richard Rorty? Para isso, tomamos como texto base o texto de Cornellis de Wall, titulado Sobre pragmatismo que foi de onde suscitou a questão para desenvolvimento do escrito e seletos comentadores.

Palavras-chave: pragmatismo; neopragmatismo; filosofia analítica.

\section{FROM MORRIS, CARNAP AND QUINE PRAGMATISM TO RICHARD RORTY NEOPRAGMATISM}

\begin{abstract}
The purpose of this paper is to present features of the pragmatic philosophy of Charles Morris, Rudolf Carnap and the mediation of Quine's philosophy to Richard Rorty's neopragmatism. The question that will guide us as the guiding question of the research is: how does the pragmatism of Morris and Carnap take place and the mediation of Quine's contribution to Richard Rorty's neopragmatism? For this, we take as base text the text of Cornellis de Wall, titled On pragmatism that was from where raised the question for the development of the writing and select commentators.
\end{abstract}

Keywords: pragmatismo; neopragmatism; analytical philosophy.

\section{INTRODUÇÃO}

O pragmatismo nasceu nos Estados Unidos entre o final do século XIX e início do século posterior também podendo ser chamado de filosofia da ação. Geovanni Reale denomina o pragmatismo como uma experiência filosófica que visa a ação para o futuro, isto é, uma perspectiva filosófica de ação ${ }^{2}$.

\footnotetext{
1 Mestrando em Filosofia pela Universidade Federal do Piauí - UFPI. Contato: arnon_psantos@ @otmail.com

${ }^{2}$ REALE, Giovanni. História da filosofia: Do Romantismo até nossos dias. São Paulo: Paulus, 1990.
} 
Ao longo deste século e sobretudo nos últimos anos a filosofia analítica tem crescido bastante com o aumento de pesquisas a esta área. De modo especial, queremos elucidar neste escrito filósofos como Rudolf Carnap (1891-1970), Charles W. Morris (1901-1979), Willard Quine (1908-2000) e Richard Rorty (1931-2007). Estes filósofos contribuem para a construção filosófica analítica em duas vertentes ou correntes filosóficas, a saber, pragmatismo e neopragmatismo.

Ao longo da leitura do livro de Cornelis de Wall com o título Sobre pragmatismo (2007) surgiu a seguinte questão para pesquisa: Como se dá a passagem do pragmatismo de Morris e Carnap e a mediação da contribuição de Quine ao neopragmatismo de Richard Rorty?Dessa maneira, queremos com esse escrito trazer de forma simples e compreensível o itinerário dos filósofos, mencionados anteriormente, para que possamos chegar ao nosso objetivo que consiste em apresentar a passagem da filosofia pragmática de Charles Morris e Rudolf Carnap e mostrar a medição da filosofia de Quine até o neopragmatismo de Richard Rorty.

\section{BREVE COMPREENSÃO DO PRAGMATISMO}

Em 1930 suponham-se que o pragmatismo havia entrado em esquecimento. Porém, ressurgiu logo depois o neopragmatismo de Richard Rorty no qual será abordado em tópicos posteriores neste escrito. Isso, porque o positivismo lógico entrava em domínio de aceitação na comunidade americana. Nestes períodos filósofos como Quine, Goodman, Pierce e Vailati acreditavam na concessão entre o pragmatismo e o empirismo lógico.

Neste escrito queremos mostrar o crescimento desses filósofos a partir da relação intelectual entre eles. Dessa maneira, percebe-se que cada um possui a sua relevância em determinado ponto para o fortalecimento na construção de conhecimento seja concordando uns com os outro sou não. Desse modo, podemos destacar a relação do pragmatismo e o positivismo lógico que compactuava da ideia empirista. Assim, para os positivistas lógicos o conhecimento é compreender as relações entre o significado de proposições e sua relação a observação que "consiste na estrutura lógica da experiência 
que pode ser comunicada ${ }^{3}$ ". Dessa maneira, não estamos falando em crenças subjetivas, mas concordâncias intersubjetivas das estruturas lógicas. A semelhança estrutural do fato com a afirmação constitui a orientação linguística, pois, relacionam a experiência a linguagem.

Segundo o que relata Wall (2007) o Congresso Internacional de Filosofia reuniu filósofos pragmatistas como Schiller e Morris aos positivistas lógicos Neurath e Carnap no ano de 1934. O intuito do congresso, anteriormente citado, era discutir sobre a análise lógica. Morris afirmava a complementariedade entre o pragmatismo e o positivismo lógico, onde se trata sobre o "significado"4. Assim, os pragmatistas explicam a relação do significado de um símbolo está contida nas expectativas dos usuários. E a relação do significado de um símbolo com a estrutura da gramática é abordagem dos positivistas lógicos. Dessa maneira, podemos encontrar como denominador comum entre os pragmatistas e os positivistas lógicos a ideia de que a perspectiva central do pragmatismo vai de encontro a uma das afirmações do positivismo lógico de que afirmações autênticas são percebidas sensorialmente. Após considerarmos características gerais do pragmatismo vamos adentrar a ideia de seus pensadores, a começar por Charles Morris.

\section{PRAGMATISMO DE MORRIS}

Charles W. Morris tentou unir o positivismo lógico ao pragmatismo norteamericano. O trabalho que o filósofo buscou no século XX através da semiótica foi a divisão entre três dimensões da ciência dos significados, a saber, sintaxe, semântica e pragmática. Essa tríade é baseada em um referencial já vindo de Charles Sanders Peirce (1839-1914) que influenciou o pensamento de Charles W. Morris acerca da questão da linguagem.

Segundo a afirmação do texto de Morris Fundamentos da Teoria dos Signos (1985), os homens predominantemente são entre os animais os que usam mais signos ${ }^{5}$,

\footnotetext{
${ }^{3}$ WAAL, Cornelis de. Sobre Pragmatismo. São Paulo: Edições Loyola, 2007, p. 191.

${ }^{4}$ WALL, op. cit., p. 93.

${ }^{5}$ MORRIS, Charles. Fundamentos da teoria dos signos. Paidós: Barcelona, 1985, p. 5. 
isto é, a civilização humana depende dos signos, por isso, é inseparável a ideia do funcionamento dos signos com a mente humana.

[...] uma justificação peculiarmente intelectualista de desonestidade no uso dos signos consiste em negar que a verdade tenha outro componente para além do pragmático, de jeito que qualquer signo que se preste aos interesses do utilizador é considerado verdadeiro ${ }^{6}[\ldots]$.

Podemos, dessa maneira chamar de verdade utilitarista da semiótica quando a verdade seja dita unilateral considerando apenas a verdade pragmática. Na consideração da verdade unilateral dos signos pela pragmática essa última, o pragmatismo, não tem pretensão de ser a verdade que se destaca e desconsidera todas as outras formas de compreensão sobre a verdade. Pelo contrário, é a partir da contraposição ou reafirmação de outras apreensões de verdade que se pode construir bases mais sólidas e práticas da verdade. Estamos a afirmar esse argumento de Morris no intuito de elucidar a verdade que por vezes é forçada na pretensão de corroborar sentenças empíricas.

A primeira dimensão da tríade da semiótica, a sintaxe, apresenta as relações dos signos entre si. A sintaxe, considerada como o estudo das relações dos signos com os signos é a mais desenrolada de todos as dimensões da semiótica, pois é a forma/ estrutura da língua. A implicação trate-se do termo que resumo a função da sintaxe na qual o signo implica em si mesmo seja na linguagem ou nos signos de modo geral. Tendo em vista que Morris tinha a pretensão de não se limitar apenas as estruturas linguísticas. Quis o filósofo alcançar uma semiótica de signos de modo genérico.

A teoria dos significados, como já mencionado anteriormente, destaca a semântica como dimensão interina da correspondência entre os signos com os objetos que aludem a sua representação. Dessa maneira, é caráter da linguagem a aplicação das regras semânticas que coordenam os significados com a combinação de seus objetos que determinam sua aplicabilidade.

Por último, acerca da terceira dimensão semiótica está a pragmática. Essa dimensão se ocupa em relacionar os signos com seus intérpretes. Neste caso, são analisadas algumas manifestações do interprete que pode despertar um signo em sua mente.

\footnotetext{
${ }^{6}$ Idem, p. 28.
}

Programas de Pós-Graduação em Ciências Sociais e Filosofia - UNIOESTE - Rua da 
Diante da apresentação sobre a compreensão da semiótica de Morris dividida em sintaxe, semântica e pragmática, como explicitado acima, pode-se perceber o vínculo pragmático da verdade. No qual, nosso filósofo, afirma que: "pragmatismo enquanto uma continuação do empirismo é uma generalização do método científico para fins filosóficos e que não poderia afirmar que os factores no uso comum do termo 'verdade', para os quais se tem vindo a chamar a atenção, aniquilariam factores reconhecidos anteriormente ${ }^{7}$. . Essa afirmativa sobre a verdade pragmática de Morris, corrobora o que tínhamos declarado no início desse tópico, de que a verdade sobre a compreensão pragmático não pode ser unilateral. Diante das evidencias sobre o pragmatismo, Morris declara a importância do mesmo ao afirmar a atenção mais profunda a relação signos e os utilizadores.

\begin{abstract}
A perspectiva mais plausível da importância permanente de pragmatismo reside no facto de ter prestado mais atenção à relação entre os signos e os seus utilizadores, do que acontecia anteriormente, e de ter acentuado mais profundamente, do que anteriormente era feito, a importância desta relação para a compreensão das actividades intelectuais ${ }^{8}$.
\end{abstract}

Visto isso, percebe-se que o pragmatismo norte-americano de Morris destaca a relação signos e intérpretes como uma nuance no pragmatismo. Assim, a necessidade dos signos também é que "contenham referência não apenas à linguagem, mas às pessoas que usam a linguagem ${ }^{9}$ ". Assim,o pragmatismo perseverou diante da afirmativa de que a mente imprescindivelmente necessita das outras para evoluir, como mencionado por Morris ao citar Charles Pierce em Pragmatismo e Empirismo Lógico ${ }^{10}$.

Em suma, segundo Wall (2007) na participação de Morris no Congresso Internacional de 1934 tinha como objetivo também mostrar a relação complementar entre o positivismo lógico e o pragmatismo ${ }^{11}$. Dessa maneira, a abordagem acerca da tríade que mostramos, acima, constitui, uma ideia continuada da filosofia de Pierce e que, por conseguinte, veremos a adesão por filósofos posteriores, a exemplo, Rudolf Carnap.

\footnotetext{
${ }^{7}$ Idem, p. 43.

${ }^{8}$ Idem, p. 32.

${ }^{9}$ MORRIS, Charles. Pragmatismand Logical Empirism. In: Schilppp, 1963, p. 88.

${ }^{10}$ Idem, p. 92.

${ }^{11}$ WAAL., op. cit, p. 92.
} 


\section{PRAGMATISMO DE CARNAP}

Carnap havia aceitado a tríade de Morris sobre a análise lógica, a saber, a pragmática, a semântica e a sintaxe. Carnap compreende a pragmática como a relação entre a linguagem e o falante de maneira que pertence a uma teoria da linguagem. Diante disso, no final de Testabilidade e Significado, Carnap declara adesão ao ponto de vista de Morris sobre o empirismo cientifico.

No livro Testabilidade e significado(1973), Carnap aborda como a questão empírica corrobora na tentativa de descobrir se uma afirmação pode ser declarada verificável, confirmável e testável. Desta maneira, em Testabilidade $e$ significado(1973), Carnap afirma que "uma sentença é testávelse conhecermos um dos métodos para testá-la; e diremos que é confirmável se soubermos sob que condições a sentença seria confirmada" "12", Desse modo, Carnap não afirma uma confirmação absoluta sobre a questão da confirmação e seus testes em uma prática. Carnap sugere que a escolha linguística em termos de seu arcabouço vale a que melhor se desempenhar.

Segundo Wall (2007) para os positivistas lógicos o método de verificação é seu significado. Dessa maneira, o verificacionismo para os positivistas lógicos ou o chamado princípio de verificabilidade possui proximidade com a pragmática no pragmatismo.

Os positivistas lógicos acreditavam fortemente que para uma afirmação ser significativa é necessário mostrar a possibilidade de sua verdade ou falsidade de acordo com a experiência, esta última que deve ser sensível. Porém, Carnap pensou essa maneira dos positivistas lógicos de modo diferente. Wall (2007), afirma que Carnap acredita que precisamos tomar decisões absolutas e conclusivas abruptamente, mas ao longo do tempo irmos confirmando e tomando confiança na verificabilidade de uma determinada sentença.

Dois conceitos são fortes na compreensão de Carnap em termos de confirmação de condições de uma sentença, a saber, confirmabilidade e testabilidade. Para se obter a

\footnotetext{
${ }^{12}$ CARNAP, Rudolf. Testabilidade e Significado. São Paulo: Nova Cultural, 1973, p. 171-213. (Coleção Os Pensadores), p. 171. 
confirmabilidade é necessário condições que confirmem a sentença. A testabilidade, segundo Carnap, está ligado a tentativa de confirmação do não da sentença.

Em um artigo de Carnap, intitulado A eliminação da metafísica através da análise lógica da linguagem (1929), o filósofo faz suas objeções a metafísica e de modo específico a Martin Heidegger. Desse modo, mediante a compreensão de Carnap, em suas virtudes pragmáticas, o estudo do sentido do ser não teria intervenção direta em sua compreensão de linguagem por não apontar a referência/significado. Assim, fazendo com que o filósofo em seu artigo, acima destacado, fizesse afirmações de que a utilidade da metafísica seria, dentre outras coisas, a demonstração do sentido da vida ${ }^{13}$. Entretanto, a proposta de Heidegger está a não restringir a linguagem à suas faculdades lógicas correspondentista. O filósofo, alemão, aponta a metafísica enquanto ontologia fundamental o que não desconsidera a lógica. Em suma, estamos a fazer essa argumentação para diferenciar a compreensão do pragmatismo encontrado em Carnap e sua oposição a ideia de linguagem advinda de Heidegger.

Na parte inicial do livro da coletânea de livros de Schlick e Carnap (1973) podemos perceber a proposta sobre o significado apresentado por Carnap através de uma confirmação gradual o que não acontece na metafísica de Heidegger. Assim uma proposição será confirmada a partir de suas experiências capazes de confirmá-las. Por conseguinte, veremos a filosofia de Quine, esta que foi grande contribuinte no século passado e atualmente ainda a filosofia analítica.

\section{QUINE COMO PONTE PARA O NEOPRAGMATISMO DE RICHARD RORTY}

Willard van Orman Quine (1908-2000) foi um grande crítico do empirismo clássico. Seu projeto filosófico encaminhou-se para a reorientação desse empirismo e seus dois dogmas que o filósofo expos em seu artigo de 1975: Dois dogmas do empirismo. Veremos a relevância do filósofo em seus outros escritos.

Quine marca uma nova maneira de tratar a linguagem, pelo prisma do externalismo, que repercute em Davidson. O problema ontológico recebe de Quine uma solução bastante polêmica e original: a única maneira de, pela

\footnotetext{
${ }^{13} \mathrm{Cf}$, CARNAP, Rudolf. The Elimination of Metaphysics Through Logical Analysis of Language. Tradução de Arthur Pap. In: Ayer, 1959, pp. 80-81. 
linguagem, haver uma "ponte" com a realidade é pelo uso da variável ligada, uma função que é exercida gramaticalmente pelo pronome e não pelo fato de ser nome de algo ou atributo de algo (adjetivo). ${ }^{14}$

Com isso, é notório dizer a partir da abordagem lógico-pragmática de Quine que o filósofo não se propõe a uma teria dos significados. Dessa maneira, a verdade não pode ser alcançada em meio à disposição das coisas. Essa compreensão da verdade da coisa na realidade se dá pelo uso da variável. Essa última, torna-se meio para a solução do problema ontológico da linguagem.

Segundo Rorty (1994) uma outra "[...] tese importante de Quine diz respeito à inescrutabilidade da referência, ligada a sua concessão holística da linguagem e da epistemologia, o assim chamado "behaviorismo epistemológico ${ }^{15}$. Desse modo, Quine não trabalha a partir de associação de palavras e ideias. Nosso filósofo, faz suas considerações a partir das propriedades dada pelo comportamento. São nesses aspectos que vamos observando, Quine, enquanto pragmatismo que é intermédio ao neopragmatismo.

Willard W. Quine enquanto jovem era adepto ao positivismo lógico por influência de seu professor Lewis em Havard. Após, visitou Carnap em Praga por suas influências com o Círculo de Viena. Passos adiante em sua filosofia, Quine resolve afirmar que os elementos de Lewis e Carnap limitava a escolha pragmática a de uma linguagem conceitual, isto é, algo já estruturado e definido. Dessa maneira, distanciavam-se de ser pragmáticos. Quine apresenta uma linguagem que em relação ao seu significado representam um corpo linguístico com suas diversas relações teóricas, conceituais, a uma forma de vida, etc ${ }^{16}$.

Para resolver a posição de Lewis e Carnap, Quine no escrito Dois dogmas do empirismo (1951), pretendeu afastar-se do dogma do reducionismo e o dogma da separação radical entre analítico e sintético. Desse modo, caminhou-se ao que Quine chamou de "pragmatismo mais completo".

Os dois dogmas que Quine buscou banir em Dois dogmas do empirismo (1951) foi o da distinção entre o enunciado analítico e sintético e o outro dogma o

\footnotetext{
${ }^{14}$ ARAÚJO, Inês Lacerda. Do signo ao discurso: introdução à filosofia da linguagem. São Paulo: Parábola Editorial, 2004, p. 150.

${ }^{15}$ RORTY apud Araújo, 2014, p. 151.

${ }^{16}$ GHIRALDELLI, Júnior Paulo. Richard Rorty: A filosofia do Novo Mundo em busca de mundos novos. Petrópolis, RJ: Vozes, 1999, p. 31. 
reducionismo. Segundo Waal (2007), considerando o primeiro dogma o analítico do enunciado verifica sua veracidade se pode ser assegurada em virtude apenas do significado de seus termos, independentemente da experiência, de tal modo que a negação de um enunciado analítico seria contraditório. Quine critica a ideia de que existe uma forma clara de fazer a distinção entre o analítico e sintético, isto é, não se tem um critério claro para distinguir um enunciado analítico do sintético.

Quine critica a distinção analítico/sintético, mostrando que a analiticidade depende da sinonímia, da definição e de regras semânticas, portanto, há uma circularidade nestes conceitos ou um apelo a componentes fáticos, o que autodestrói o conceito de analítico ${ }^{17}$.

Quine destaca a necessidade do empirismo sem dogmas. Assim, a distinção entre enunciados analíticos e sintéticos não proporcionam a revisão de enunciados. Desse modo, para Quine o valor autêntico em sentido de verdade pode sofrer alteração na medida em que se agremia em meio a outros enunciados.

O segundo dogma apresentado por Quine foi a ideia de que "todo enunciado significado pode ser traduzido num enunciado acerca da experiência imediata" ${ }^{18}$. Assim a ideia tirada por Quine sobre o reducionismo é a de que é necessário uma análise que não seja isolada sobre o mundo, isto é, um enunciado separado em si mesmo não possui acepção empírica.

Quine impulsiona o movimento pragmatista de Rorty no que tange ao clima holístico. Dessa maneira, o holismo "é aquela posição na qual todas as sentenças se diferem por graus, não por espécie ${ }^{19}$ ", Assim, as relações do significado com o corpo linguístico confere a ideia aceita por Rorty de que o "holismo está no centro da posição pragmatista na medida em que ser pragmatista é ser contextualista ou antiessecialista" ${ }^{20}$. Desse modo, uma das pontes a filosofia pragmatista de Quine a filosofia de Rorty é a ideia de que os enunciados se diferem por graus no tange a doutrina holística.

\section{BREVE COMPREENSÃO DO NEOPRAGMATISMO}

\footnotetext{
${ }^{17}$ ARAÚJO, Inês Lacerda. Do signo ao discurso: introdução à filosofia da linguagem. São Paulo: Parábola Editorial, 2004, p. 156.

${ }^{18}$ WAAL, op. cit., 2007, p. 200.

${ }^{19}$ GHIRALDELLI, op., 1999, p.31.

${ }^{20}$ Idem. 
O neopragmatismo é uma corrente filosófica que surgiu em meados do século $\mathrm{XX}$ que tem como base o pragmatismo. O neopragmatismo buscou colocar em evidência alguns conceitos do pragmatismo. Também chamado de pragmatismo da linguagem ou pragmatismo linguístico o neopragmatismo é um termo do século anterior e assim recentemente empregado que busca centralizar a experiência linguística.

Dessa maneira, os neopragmatistas ficaram mais próximos da filosofia do século XX de Willard Quine que abordamos anteriormente. Considera-se Quine, como o último pragmatista e, aquele pelo qual aponta uma nova visão ou reestruturação ao pragmatismo. Durante esse período a filosofia analítica contou com filósofos neopragmatista como: Hilary Putnam (1926-2016), Donald Davidson (1917-2003), etc.

\section{RICHARD RORTY E O NEOPRAGMATISMO}

Richard Rorty cresceu em meio ao pragmatismo. Porém na Universidade de Chicago sofreu influências do ambiente acadêmico contra o pragmatismo. Desiludido do que vivera em Chicago, Rorty retorna ao pragmatismo e agora influenciado por Dewey. O livro O espelho da natureza (1979) é caractere de seu retorno ao pragmatismo.

Na metáfora do espelho implica a possibilidade de um ponto de vantagem neutro - um perto que é independente de nossas vontades e nossos desejos, de nossas preocupações e nossas idiossincrasia - e fez disso seu padrão ${ }^{21}$.

Nesta citação, acima, podemos confirma a perspectiva de Jonh Searle acerca do realismo externo, isto é, uma realidade independente da mente? Assim tendo em vista características do espelho que reflete não a interpretação de algo, mas a realidade que independe daquilo que se pensa sobre o que se ver, mas se reflete no espelho. Searle também afirma que é o realismo externo não é uma teoria, mas a teoria das teorias da realidade.

Na perspectiva de Rorty as impressões sensíveis não devem ser negadas como conhecimento. Aqueles que buscam somente fundamentar as crenças em impressões

\footnotetext{
${ }^{21}$ WAAL, op. cit., 2007, p. 208.

Programas de Pós-Graduação em Ciências Sociais e Filosofia - UNIOESTE - Rua da Faculdade 645. Toledo - PR. CEP 85.903-000 Email: revistaalamedas@gmail.com
} 
sensíveis enganam a formação da sensibilidade coma justificativa que acontece pela linguagem.

Vemos em Rorty, mais uma vez, que ele acrescenta ao pragmatismo com sua necessidade de impressão sensível a linguagem. Em justificação da crença, segundo Rorty, necessita de um consenso que conduza a produção estabelecida. Assim, a compreensão de verdade do pragmatismo clássico é resquício na filosofia de Rorty. Pois, “[...] a verdade representa simplesmente aquilo que se revela útil enquanto objeto de crença $^{22}$ [...]. Compreensões como essas são partes do arcabouço que fora força propulsora para o neopragmatismo de Rorty.

Segundo a visão de Rorty o pragmatismo não deve ser apenas apresentado como teoria, tão pouco como um sistema dado pela filosofia. Daí que surge um novo movimento filosófico a partir das ideias de Rorty, o neopragmatismo.

Para o pragmatismo clássico a experiência é um conceito que ultrapassa a esfera da linguagem, podendo até mesmo atingir formas pré-linguísticas, ao passo que Rorty, ao se engajar na virada linguística, de fato opera a substituição de um conceito pelo outro, fazendo a linguagem ocupar no neopragmatismo a posição que a experiência dantes ocupava no pragmatismo $^{23}$.

A segunda variação relevante entre o pragmatismo original e sua nova versão se dá em torno da ideia de linguagem. O neopragmatismo de Rorty, de certa forma, substitui o conceito pragmatista de experiência pelo de linguagem ou realça este em detrimento daquele. Dessa maneira, podemos notar que "para Rorty, mudar como uma pessoa vê o mundo significa mudar como uma pessoa fala sobre ele. Tal mudança de vocabulário não é, além disso, um caso de lógica ${ }^{24, "}$. Segundo Rorty a linguagem está intrinsecamente inserida na visão de mundo de cada um de nós. De maneira que o mundo é uma construção linguística.

\section{CONSIDERAÇÕES FINAIS}

\footnotetext{
${ }^{22}$ RORTY, Richard 1993. Solidariedade ou objetividade? Novos Estudos, 36, p. 111.

${ }^{23}$ POGREBINSCHI, Thamy. Será o neopragmatismo pragmatista? Novos estudos. CEBRAP $\mathrm{n}^{\circ}$.74 São $\quad$ Paulo Mar. 2006, $\quad$ p. $130 . \quad$ Disponível <http://www.scielo.br/pdf/nec/n74/29643.pdf>. Acesso em: 18 Jun. 2018.

${ }^{24}$ WAAL., op. cit, p. 219. 
Levando-se em consideração os aspectos destacados da filosofia de Charles Morris, Rudolf Carnap, Willard Quine e Richard Rorty retomamos as considerações propostas na introdução de abordar clara e sinteticamente alguns dos aspectos principais desses filósofos a filosofia analítica.

$\mathrm{Na}$ filosofia pragmática de Charles Morris destacamos a tríade sintaxe, semântica e pragmática. A proposta de Morris era de que o pragmatismo e o positivismo lógico são complementares. Assim, os pragmatistas procuravam fazer conexão entre o significado com as expectativas da utilidade e os empiristas lógicos inserem a relação do significado com a sintática da linguagem.

Por conseguinte, a Morris e sua adesão a tríade, acima mencionada, já dada por Pierce, Carnap aceita esses três pontos sobre a análise lógica. Desse modo, Carnap assegura que podemos tomar enunciados conclusivos abruptamente, mas é necessário deixar que a confirmação cresça em autenticidade juntamente com a verificabilidade e testabilidade.

Willard Quine apresenta a linguagem através de um corpo linguístico, isto é, uma conexão de vários elementos que formam um todo. Para Quine, o valor de verdade pode sofrer alteração na medida em que se confronta com outros enunciados. Com Quine chega-se a compreensão, já defendida no desenvolvimento do escrito, sobre sua "doutrina holística do significado" que proclama o significado em suas relações com um corpo linguístico.

A filosofia de Quine possui conexão ou faz-se como ponte ao neopragmatismo de Richard Rorty ao ser denominado como o último pragmatista e aquele que faz a inserção da linguagem como eixo central. Dessa maneira, podemos retomar ao que afirmamos na introdução do neopragmatismo como sendo o pragmatismo linguístico.

Em suma, nosso propósito foi percorrer pontos centrais da filosofia de Morris, Carnap, Quine e Rorty e assim observar passagem da filosofia pragmática de Charles Morris, Rudolf Carnap e a mediação da filosofia de Quine até o neopragmatismo de Richard Rorty.

\section{BIBLIOGRAFIA}

ARAÚJO, I. L. Do signo ao discurso: introdução à filosofia da linguagem. São Paulo: Parábola Editorial, 2004. 
CARNAP, R. Testabilidade e Significado. In: Coleção os Pensadores. São Paulo: Nova Cultural, p. $171-213,1973$.

The elimination of metaphysics through logical analysis of language.

Tradução de Arthur Pap. In: Ayer, 1959.

MORRIS, C. Fundamentos da teoria dos signos. Tradução de António Fidalgo. Universidade da Beira Interior, 1985. Disponível em: $<$ http://biblioteconomiadigital.blogspot.com.br/2011/01/fundamentos-da-teoria-dossignos.html>. Acesso em: jan. 2019.

Pragmatism and logical empirism. In: Schilppp, 1963.

POGREBINSCHI, T. Será o neopragmatismo pragmatista?. Novos estudos. CEBRAP, $\mathrm{n}^{\circ} .74$ São Paulo Mar. 2006. Disponível em: <http://www.scielo.br/pdf/nec/n74/29643.pdf >. Acesso em: 18 Jun. 2018.

QUINE, W. V. O. Dois dogmas do empirismo. In: RYLE et al. Coleção os Pensadores. Vol. LII. São Paulo: Abril S.A. Cultural e Industrial, 1975. p. 237- 254.

RORTY, Richard 1993. Solidariedade ou objetividade? Novos Estudos, 36.

RORTY, R. A filosofia e o espelho da natureza. Tradução de Antonio Trânsito. Rio de Janeiro: Relume Dumará, 1994.

WAAL, Cornelis de. Sobre pragmatismo. São Paulo: Edições Loyola, 2007. 